\title{
New Forming Process of Three-Dimensionally Shaped Magnesium Parts Utilizing High-Strain-Rate Superplasticity
}

\author{
Akira Takara $^{1}$, Yukio Nishikawa ${ }^{1}$, Hiroyuki Watanabe ${ }^{2}$, Hidetoshi Somekawa ${ }^{3}$, \\ Toshiji Mukai ${ }^{4}$ and Kenji Higashi ${ }^{3}$ \\ ${ }^{1}$ Production Core Engineering Laboratory, Matsushita Electric Industrial Co., Ltd., Kadoma 571-8502, Japan \\ ${ }^{2}$ Department of Mechanical Engineering, Osaka Municipal Technical Research Institute, Osaka 536-8553, Japan \\ ${ }^{3}$ Department of Metallurgy and Materials Science, Osaka Prefecture University, Sakai 599-8531, Japan \\ ${ }^{4}$ Research Center for Advanced Science and Technology, The University of Tokyo, Tokyo 153-8904, Japan
}

The applicability of high-strain-rate superplasticity for forming magnesium parts, especially structural component with a boss on a plate designed with the aim of producing mobile electric appliances, was examined. The required microstructure and grain refinement process for target forming was examined prior to the forming trials. Following the examination of the processing design, the high-strain-rate superplastic AZ91 magnesium alloy with a required grain size less than $3.2 \mu \mathrm{m}$ was produced by hot extrusion under the condition that the Zener-Hollomon parameter was $3 \times 10^{12} \mathrm{~s}^{-1}$. It was experimentally confirmed that a boss with a height greater than $5 \mathrm{~mm}$, which is a requirement for electric appliances, could be formed within $10 \mathrm{~s}$ even at a low temperature of $523 \mathrm{~K}$ using this high-strain-rate superplastic magnesium alloy. Basic knowledge related to the formation of three-dimensionally shaped magnesium parts by utilizing high-strain-rate superplasticity was obtained.

(Received February 16, 2004; Accepted June 11, 2004)

Keywords: high-strain-rate superplastic forming, magnesium alloys, hot extrusion, grain size, Zener-Hollomon parameter

\section{Introduction}

Currently, environmental issues have led to a trend wherein plastic parts that are employed as structural components are being replaced by metallic materials. The reason behind this is that metallic materials are in general readily recyclable. In addition, this replacement is essential to reduce the weight and size of appliances, especially mobile electronic appliances such as cellular phones and notebook computers. Magnesium alloys are one of the promising replacements for plastics. This is not only due to the relatively low density of magnesium but also due to its relatively high modulus heat dissipation, electromagnetic shielding, and "metallic feel" that gives a sense of quality. Therefore, platform science and technology for advanced magnesium alloys has been widely researched. ${ }^{1)}$

Die casting has been the principal technique employed when fabricating magnesium components on account of its high productivity, adequate strength, quality, and dimensional control that can be exerted. ${ }^{2,3}$ Fabrication is also performed by the semi-solid thixo-molding process. ${ }^{3-5}$ ) However, these techniques face the following disadvantages: (i) a thin sheet with a thickness $<0.5 \mathrm{~mm}$ is difficult to cast, (ii) inner voids are easily formed, (iii) cast materials possess lower strength and ductility when compared with wrought materials, (iv) solidification time in a mold is longer, (v) casting machines are large and expensive, and (vi) the magnesium alloy melt must be covered with a shielding gas such as $\mathrm{SF}_{6}$ or Ar to prevent burning. Therefore, it is expected that a process that utilizes plastic forming will be developed. Currently, deep drawing has already been commercialized in forming the housings of minidisk stereo players. ${ }^{6)}$ This is because the ductility of magnesium alloys improves to some extent at elevated temperatures, although magnesium alloys normally exhibit limited ductility near room temperature. However, it is impossible to develop protrusions on the plate such as the boss, which is required for the connection to other parts and the rib, which is required to position or separate the parts. In order to apply magnesium alloys to various parts, the plastic forming technique that can produce complicated three-dimensionally shaped parts needs to be developed. Recently, a hot forging process termed as press-forging had been developed in Japan. It was applied for the production of the minidisk stereo player housings. ${ }^{7)}$ However, this process requires high forming temperatures of 573-673 K and large load of $1,960-4,900 \mathrm{kN}$.

The superplasticity of various materials is an extreme example of high ductility at elevated temperatures. ${ }^{8-12)}$ Superplastic forming is one of the viable techniques that can be used to fabricate magnesium into complex shapes under low flow stress. ${ }^{13,14)}$ In addition, high-strain-rate superplasticity, defined as superplasticity occurring at strain rates at or above $10^{-2} \mathrm{~s}^{-1},{ }^{15)}$ is expected to result in economically-viable, near-net-shape forming techniques under the commercial hot working rate. ${ }^{16)}$ However, superplastic forming of magnesium-based materials has not been employed in industries as yet, despite the fact that several magnesium alloys processed by ingot metallurgy exhibited superplasticity. ${ }^{17-22)}$

The applicability of high-strain-rate superplasticity for the formation of magnesium parts was examined in the present study. It was demonstrated that a boss with a height greater than $5 \mathrm{~mm}$, which is sufficient for connection with the other parts, could be formed within $10 \mathrm{~s}$ even at a relatively low temperature of $523 \mathrm{~K}$ for a high-strain-rate superplastic AZ91 magnesium alloy. Forming trials based on the processing design developed in the present study (shown in Fig. 10) were found to be very useful. Thus, by considering the required microstructure and grain refinement process in advance, the forming prototype could be performed without trial and error. 
Table 1 Required specifications for the boss forming of electric appliance structural parts.



2. The Required Microstructure and Material Preparation for High-strain-rate Superplastic Forming

\subsection{Required microstructure}

The formability required for the structural parts of cellular phones, which are considered to be representative of small mobile electronic appliances, was determined for experimental forming. The shape requirements for the parts are listed in Table 1. The height of a boss is required to be $5 \mathrm{~mm}$ when it is used as a structural part in cellular phones.

Productivity should be taken into consideration for mass production. In order to achieve an advantage in the production cost as compared with the competitive forming processes, the forming needs to be completed within $10 \mathrm{~s}$. If a boss with a height of $5 \mathrm{~mm}$ is to be formed within $10 \mathrm{~s}$, a boss forming speed $\geq 0.5 \mathrm{~mm} / \mathrm{s}$ is required. Pressing speed $\geq 0.025 \mathrm{~mm} / \mathrm{s}$ is required when the ratio of the boss area to the plane area is $1 / 20$. The corresponding forming strain rate, $\dot{\varepsilon}_{\mathrm{F}}$, may be estimated using the following equation developed for direct extrusion: ${ }^{23)}$

$$
\dot{\varepsilon}_{\mathrm{F}}=\frac{6 v d_{0}^{2}}{\left(d_{0}{ }^{3}-d_{1}^{3}\right)} \ln \left(\frac{d_{0}^{2}}{d_{1}^{2}}\right) \tan \theta,
$$

where $v$ is the pressing speed, $d_{0}$ is the container diameter, $d_{1}$ is the extrusion diameter, and $\theta$ is the semi-angle of conical die or the dead metal zone. In the present boss forming, $d_{0}$ and $d_{1}$ represent the initial diameter of the specimen in the plane region and the diameter of the boss, respectively. When the boss diameter is $4 \mathrm{~mm}$ and the ratio of the boss area to the plane area is $1 / 20$, the target strain rate to perform boss formation within $10 \mathrm{~s}$ is calculated to be $\geq 2.5 \times 10^{-2} \mathrm{~s}^{-1}$. The strain rate is in the range of the definition of high-strainrate superplasticity $\left(\dot{\varepsilon} \geq 1 \times 10^{-2} \mathrm{~s}^{-1}\right)$.

The forming temperature also plays an important role in mass production. A forming temperature below $523 \mathrm{~K}$ enables (i) the use of hydrocarbon oil as a lubricant, (ii) the use of fluorine rubber as parts of the conveying equipment, (iii) the life of metal dies to be prolonged, and (iv) the prevention of grain growth during preheating. ${ }^{24)}$ Therefore, we aimed at conducting the formation below $523 \mathrm{~K}$.

Since formability is strongly dependent on the grain size under superplastic flow, ${ }^{16)}$ the required microstructure for target forming was considered. The grain size for meeting the forming requirements was estimated on the basis of the constitutive equations for high temperature deformation. Generally, the constitutive equation to describe high temperature deformation is expressed as: $:^{25)}$

$$
\dot{\varepsilon}=A\left(\frac{G b}{k T}\right)\left(\frac{b}{d}\right)^{p}\left(\frac{\sigma-\sigma_{0}}{G}\right)^{n} D_{0} \exp \left(-\frac{Q}{R T}\right),
$$

where $\dot{\varepsilon}$ is the strain rate, $A$ is a constant, $\sigma$ is the flow stress, $\sigma_{0}$ is the threshold stress, $G$ is the shear modulus, $k$ is the Boltzmann's constant, $n$ is the stress exponent, $d$ is the grain size, $b$ is the Burgers vector, $p$ is the grain size exponent, $T$ is the absolute temperature, $D_{0}$ is the pre-exponential factor for diffusion, $R$ is the gas constant, and $Q$ is the activation energy, which is dependent on the rate controlling process. The threshold stress is generally observed in materials containing second phase particles. ${ }^{25)}$ In a superplastic AZ91 alloy, a $m$-value of 0.5 has been reported despite the dispersion of precipitates. ${ }^{26)}$ This is indicative of a negligible threshold stress in this alloy. Furthermore, the flow stress in the present forming is predicted to be at the high end of the superplastic region, and it is large value when compared with the threshold stress. Therefore, the threshold stress was assumed to be zero in the present study. We considered three modes of deformation for the possible mechanisms: (i) slip accommodated grain boundary sliding process $(n=2)$, which is accepted as the dominant deformation mechanism for superplastic flow, (ii) glide-controlled dislocation creep $(n=3)$, and (iii) climb-controlled dislocation creep $(n=5)$. The equation proposed by Sherby and Wadsworth ${ }^{27)}$ was used for slip accommodated grain boundary sliding process. It has been confirmed that the equation can be applied to the behavior of fine-grained magnesium alloys. ${ }^{28)}$ The phenomenological relations for climb-controlled dislocation creep in magnesium $(n=5)$ were constructed by Frost and Ashby, ${ }^{29)}$ and those for glide-controlled dislocation creep in the $\mathrm{Mg}-\mathrm{Al}$ solid solution alloys $(n=3)$ have been proposed by Watanabe $e t$ al. ${ }^{28)}$ The set of parameters in eq. (2), which express each deformation process are listed in Table 2.

The relationship between flow stress and strain rate for

Table 2 Parameters in constitutive equation.

\begin{tabular}{ccccccc}
\hline Deformation mechanism & $A$ & $p$ & $n$ & $D_{0}, \mathrm{~m}^{2} \mathrm{~s}^{-1}$ & $Q, \mathrm{~kJ} / \mathrm{mol}$ & Ref. \\
\hline $\begin{array}{c}\text { Slip accommodated } \\
\text { grain boundary sliding }\end{array}$ & $1.9 \times 10^{5}$ & 3 & 2 & $5.0 \times 10^{-12} / \delta^{*}$ & 92 & $27)$ \\
Glide controlled dislocation creep & $3.0 \times 10^{-2}$ & 0 & 3 & $1.2 \times 10^{-3}$ & 143 & $28)$ \\
Climb controlled dislocation creep & $1.2 \times 10^{6}$ & 0 & 5 & $1.0 \times 10^{-4}$ & 135 & $29)$ \\
\hline
\end{tabular}

$*: \delta$ is the grain boundary width ( $\delta$ was taken to be $2 \mathrm{~b}$ in the present analysis). 


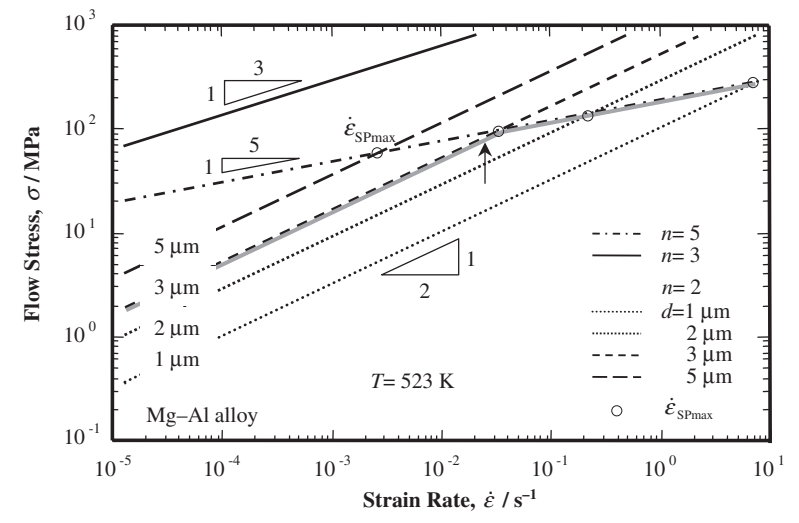

Fig. 1 The relationship between flow stress and strain rate for slip accommodated grain boundary sliding process $(n=2)$, glide-controlled dislocation creep $(n=3)$, and climb controlled dislocation creep $(n=5)$ at a temperature of $523 \mathrm{~K}$.

three deformation modes at a temperature of $523 \mathrm{~K}$ is shown in Fig. 1. Since all the three processes are considered to be independent, the fastest process is the rate-controlling one. The predicted behavior of a material with a grain size of $3 \mu \mathrm{m}$ is given by the shaded curve. Although we considered the condition for $n=3$ deformation, this model was not relevant at $523 \mathrm{~K}$. An arrow in Fig. 1 indicates the target strain rate. Figure 1 reveals that for a material with a given grain size, there exists a maximum strain rate where $n=2$ deformation is no longer the dominant process; another mode of deformation becomes important, i.e., $n=5$ deformation. The point of intersection in Fig. 1 represents the maximum strain rate for superplastic flow, $\dot{\varepsilon}_{\text {SPmax }}$. The prediction of $\dot{\varepsilon}_{\text {SPmax }}$ is shown in Fig. 2. This prediction map is beneficial when determining the grain size required to meet the desired formability at a given strain rate and temperature. The variation in grain size as a function of $\dot{\varepsilon}_{\text {SPmax }}$ at temperatures of $473,523,573$, and $623 \mathrm{~K}$ is shown in Fig. 2(a). This figure demonstrates the significant influence of grain size on

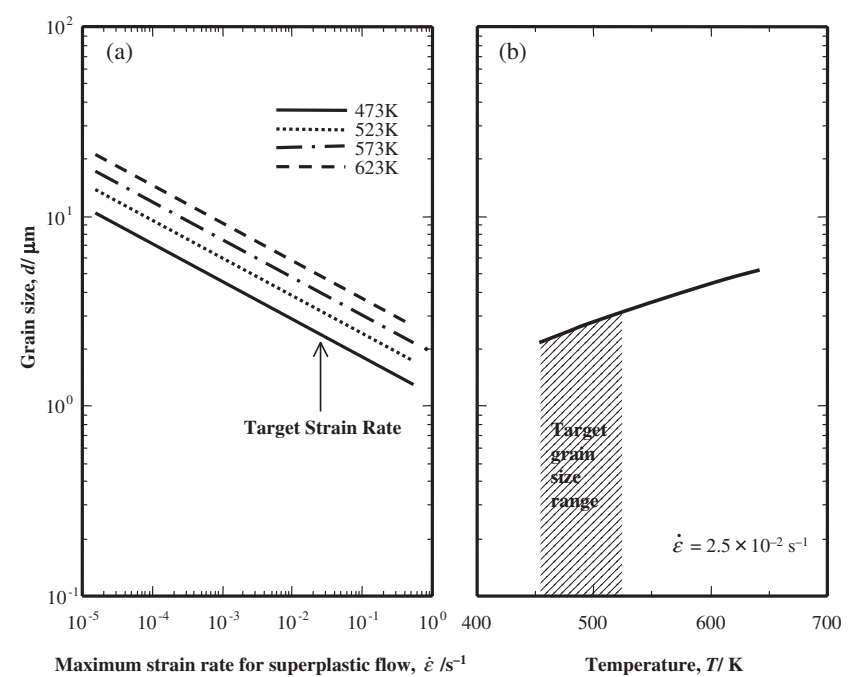

Fig. 2 (a) The variation in grain size as a function of maximum strain rate for superplastic flow, above which superplastic flow is no longer the dominant process. (b) The variation in grain size as a function of temperature at strain rate for superplastic flow of $2.5 \times 10^{-2} \mathrm{~s}^{-1}$. maximum strain rate for all temperatures. The maximum strain rate increases with decreasing grain size. The relationship between grain size and deformation temperature at $\dot{\varepsilon}_{\text {SPmax }}=2.5 \times 10^{-2} \mathrm{~s}^{-1}$ is shown in Fig. 2(b). The target grain size required to carry out plastic forming at the target conditions of strain rate above $2.5 \times 10^{-2} \mathrm{~s}^{-1}$ and temperatures below $523 \mathrm{~K}$ under superplastic flow is given by the shaded area in Fig. 2(b). For example, Fig. 2(b) indicates that the target grain size should be less than $3.2 \mu \mathrm{m}$ at a temperature of $523 \mathrm{~K}$.

\subsection{Material preparation}

It was observed that the material with a grain size $\leq 3.2 \mu \mathrm{m}$ is required to carry out boss forming within $10 \mathrm{~s}$ at $523 \mathrm{~K}$. It has been pointed out that hot deformation accompanied by dynamic recrystallization (DRX) is a promising method for refining the microstructure of magnesium alloys ${ }^{30)}$ on account of its low stacking fault energy. ${ }^{31)}$ To date, grain refinement by DRX during hot deformation has been demonstrated in pure $\mathrm{Mg},{ }^{32,33)} \mathrm{Mg}-\mathrm{Al}$ alloy, ${ }^{34)} \mathrm{Mg}-\mathrm{Al}-\mathrm{Zn}$ alloys, ${ }^{35-38)}$ and $\mathrm{Mg}-\mathrm{Zn}-\mathrm{Zr}$ alloys. ${ }^{39-45)}$ Kaibyshev et al. ${ }^{39)}$ demonstrated that grain refinement could be achieved in the ZK60 alloy by increasing the $Z$-parameter $(Z=\dot{\varepsilon} \exp (Q /$ $R T)) .{ }^{46)}$ Furthermore, Mabuchi et al. ${ }^{47)}$ also reported that the grain size of chip-extruded AZ91 alloy decreased with a decrease in the extrusion temperature, and that grain refinement could be achieved with an increase in the $Z$-parameter. This experimental evidence suggests that the following strategies be followed for grain refinement in magnesium: (i) increase the strain rate or (ii) decrease the temperature of the process. The relationship between the recrystallized grain size and Z-parameter for AZ91 alloy processed by hot working the ingot is summarized in Fig. $3 .^{26,47-52)}$ The typical strain rate range for extrusion in metals and alloys is between $10^{-1}$ and $\left.10^{2} \mathrm{~s}^{-1} .53,54\right)$ However, the extrusion at high strain rates will require large extrusion machines. Therefore, the strain rate was tentatively taken to be between $5 \times 10^{-2}$ and $5 \times 10^{-1} \mathrm{~s}^{-1}$ so as to agree with other extrusion strain rate in magnesium alloys in the literature, when the information on strain rate data was unavailable. The recrystallized grain size is roughly fitted in a bold straight line with a slope of -0.33 as shown in Fig. 3 as well as Ref. 51. This figure suggests that a $Z$-value $\geq 2 \times 10^{12} \mathrm{~s}^{-1}$ is required for hot deformation to

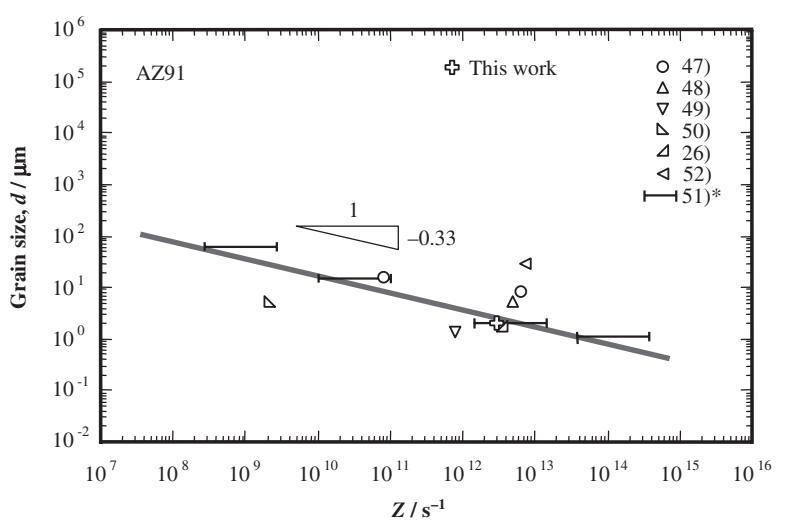

Fig. 3 The relationship between grain size and $Z$-parameter in ingot metallurgy AZ91 alloys processed by hot extrusion. 


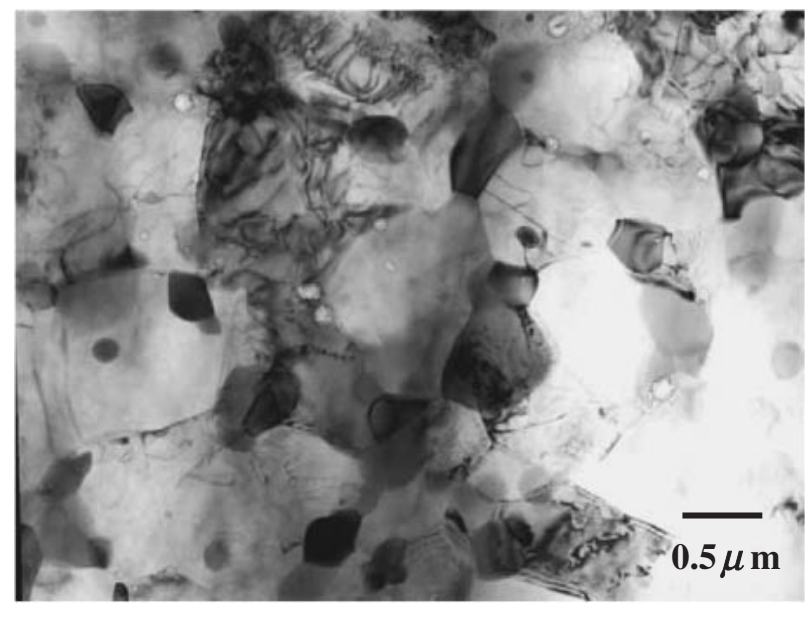

Fig. 4 Typical microstructure of AZ91 alloy after extrusion at a temperature of $523 \mathrm{~K}$ in the longitudinal section.

obtain the materials with grain sizes $\leq 3 \mu \mathrm{m}$.

Hot working was applied to a commercial $\mathrm{Mg}-\mathrm{Al}-\mathrm{Zn}$ alloy AZ91 in present study. Because this alloy is a popular commercial magnesium alloy, and the surface treatment technique has already been developed. Hot extrusion was performed in order to carry out hot deformation under the condition of $Z \geq 2 \times 10^{12} \mathrm{~s}^{-1}$ in this alloy. The AZ91 alloy was received as an ingot. The alloy was solution treated at $686 \mathrm{~K}$ for $48 \mathrm{~h}$ before extrusion. The material that was in a bar form was extruded to a sheet form with a reduction ratio of 44. The extruded sheets had a thickness of $1.4 \mathrm{~mm}$ and a width of $30 \mathrm{~mm}$. The extrusion conditions were a temperature of $523 \mathrm{~K}$ and a constant ram velocity of $0.2 \mathrm{~mm} / \mathrm{s}$. The estimated equivalent strain rate during extrusion was $1 \times$ $10^{-1} \mathrm{~s}^{-1}$ using eq. (1). The $Z$-value was calculated to be approximately $3 \times 10^{12} \mathrm{~s}^{-1}$ in the present extrusion.

The TEM microstructure of as-extruded AZ91 is shown in Fig. 4. The microstructure was composed of equiaxed matrix grains and uniformly dispersed fine particles. It was observed that the particles reside at the grain boundaries. The particles appear to be those of $\mathrm{Mg}_{17} \mathrm{Al}_{12} .{ }^{3)}$ The matrix grain size, $d$ $(d=1.74 L ; L$ is the linear intercept size), of the as-extruded material was measured to be $2.0 \mu \mathrm{m}$. It is noted that the finegrained material that exhibits high-strain-rate superplasticity was developed during only hot extrusion.

\section{High-strain-rate Superplastic Forming Trials}

\subsection{Experimental procedure}

The boss forming was experimentally confirmed using high-strain-rate superplastic AZ91 magnesium alloy. Commercially available rolled AZ31 sheet was also examined for reference. The rolled sheet with a thickness of $1.4 \mathrm{~mm}$ had an initial grain size of $22 \mu \mathrm{m}$. The schematic illustration of the die configuration for the boss forming is shown in Fig. 5(a). The shape of the designed part is shown in Fig. 5(b). The boss is formed into a cone shape at the center of the specimen with a base diameter of $4 \mathrm{~mm}$ and a semi-angle of $2.4^{\circ}$. The lower die had a hole with a depth of $12 \mathrm{~mm}$ and it opened out into the vent. The specimen with a diameter of $18 \mathrm{~mm}$ was placed on the lower die. In the present forming process, the ratio of
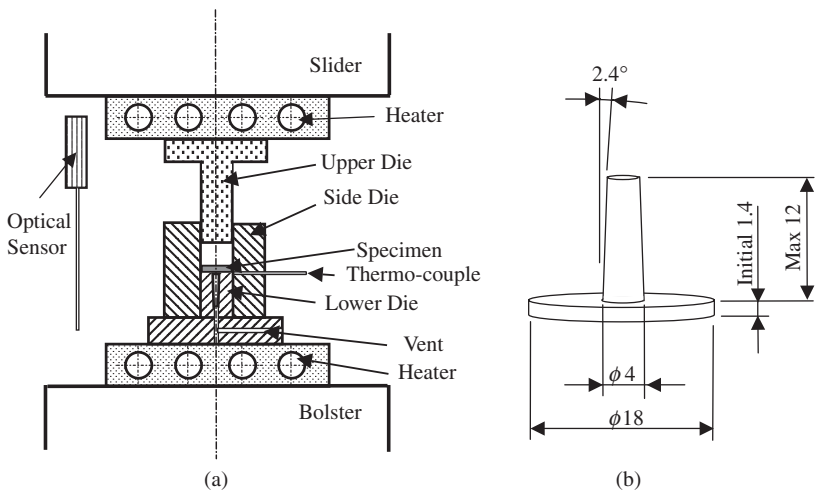

(b)

Fig. 5 (a) The schematic illustration of die configuration for boss forming. (b) The shape of designed part.

the boss area to the plane area was designed to be $1 / 20$. Pressing was performed with a hydraulic press. The specimen and dies were heated with built-in heaters on the bolster and the slider of the press. The forming temperature was measured by the thermo-couples set up in the vicinity of the specimen. The instantaneous thickness of the specimen during deformation was estimated from the position of the slider, which was measured by an optical displacement sensor every $0.1 \mathrm{~s}$. The forming process was performed at a constant pressure of $147 \mathrm{kN}$ and at a temperature of $523 \mathrm{~K}$. The specimen was lubricated with $\mathrm{MoS}_{2}$ powder.

\subsection{Results}

The appearance of the formed parts is shown in Fig. 6. The forming process was performed at $523 \mathrm{~K}$ and stopped at 10 and $60 \mathrm{~s}$. Macroscopic defects such as crack or incompletely formed region could not be observed on the surface. Furthermore, a good axial symmetry was observed in the formed parts. The reproduction of fine details appears to be good, as evidenced by the reproduction of machining marks from the die surface onto the formed parts. The height of the boss in high-strain-rate superplastic AZ91 was larger than that of the commercial AZ31 rolled sheet.

A variation in the height of the boss estimated from an

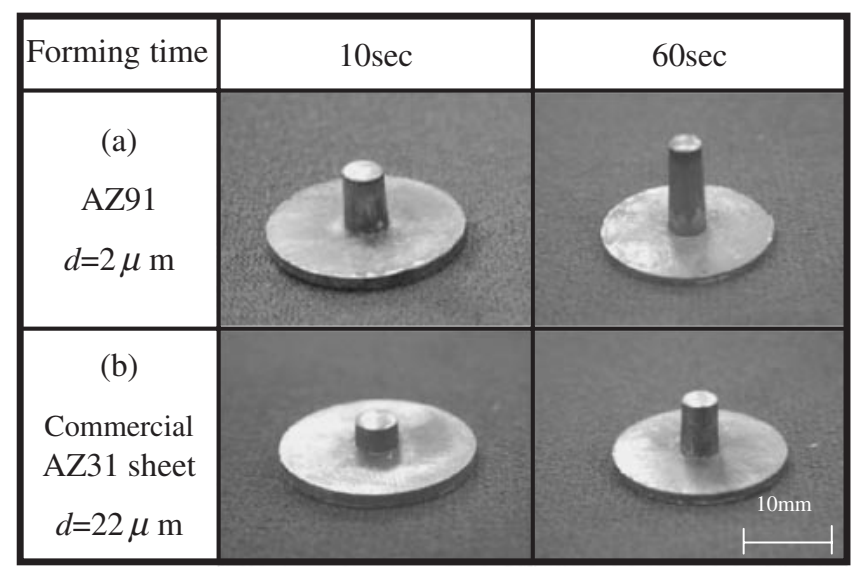

Fig. 6 Appearance of formed parts. The original specimens were taken from (a) high-strain-rate superplastic AZ91 alloy, (b) commercially available AZ31 rolled sheet. 




Fig. 7 The variation in height of the boss as a function of forming time.

instantaneous thickness of the specimen as a function of the forming time is shown in Fig. 7. The actual height of the boss at 10,20 and $60 \mathrm{~s}$ is also plotted using symbols. The actual height roughly corresponded with the estimate obtained from the position of the slider. This indicates that the specimen deformed uniformly. The height of the boss increased with the forming time. The target boss height of $5 \mathrm{~mm}$ was successfully formed within $10 \mathrm{~s}$ even at a relatively low temperature of $523 \mathrm{~K}$ by utilizing the high-strain-rate superplastic AZ91 prepared in the present study. The present forming temperature was reduced by $50-150 \mathrm{~K}$ when compared with the conventional plastic forging process. The boss could be formed to a height $>5 \mathrm{~mm}$ within $10 \mathrm{~s}$ and above $10 \mathrm{~mm}$ after $60 \mathrm{~s}$. On the other hand, the boss in a commercial rolled sheet did not attain a height of $5 \mathrm{~mm}$ within $10 \mathrm{~s}$. The flow velocity was gradually decreased from $1 \mathrm{~mm} / \mathrm{s}$ at $5 \mathrm{~s}$ to $0.1 \mathrm{~mm} / \mathrm{s}$ at $30 \mathrm{~s}$ even in the high-strain-rate superplastic alloy. This is probably due to the increase in frictional resistance between the boss and the die.

The variation in the forming strain rate and forming time is shown in Fig. 8. The strain rate was calculated from the slope of the curve shown in Fig. 7. In the early stages of deformation, the strain rate ranged from $8 \times 10^{-2}$ to $2 \times 10^{-2} \mathrm{~s}^{-1}$. It is evident that although the forming strain rate gradually decreased with time, the present forming was performed under the high-strain-rate superplastic condition.

The typical TEM microstructure in the boss region is

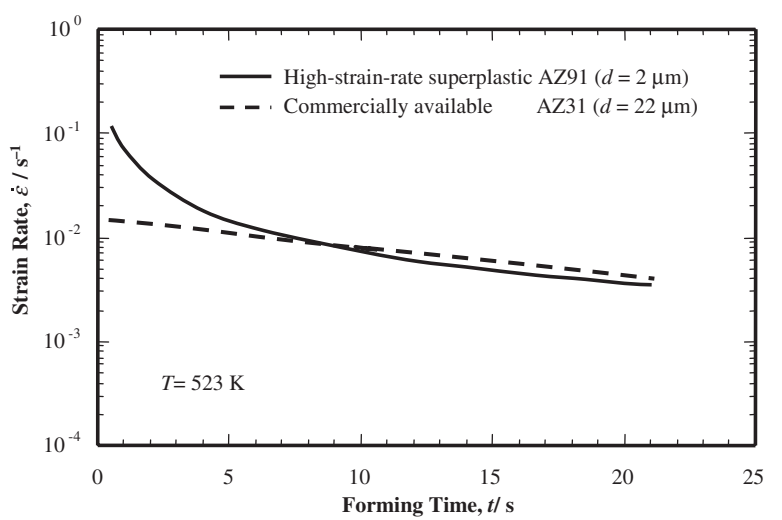

Fig. 8 The variation in strain rate as a function of time during boss forming.

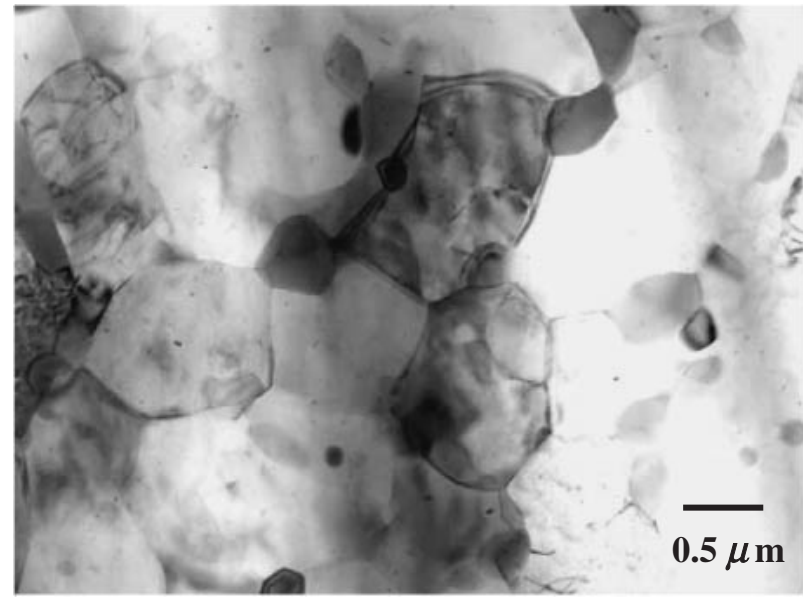

Fig. 9 Typical microstructure of the boss region in the longitudinal section.

shown in Fig. 9 for high-strain-rate superplastic AZ91 alloy. The microstructure in the boss region revealed that the grains are not elongated along the flow direction. This confirms that the grain boundary sliding substantially contributes to the total strain in the present alloy as well as in conventional superplastic materials. It is evident that the boss was formed in the superplastic region. The grain size of the boss region was measured to be $2.3 \mu \mathrm{m}$. The coarseness of the grains slightly increased after forming, probably as a result of straininduced grain growth.

\section{Conclusions}

The applicability of high-strain-rate superplasticity for the formation of three-dimensionally shaped parts was examined in AZ91 magnesium alloy according to the flow chart shown in Fig. 10. The authors established the relationship between the required microstructure for high-strain-rate superplastic forming and processing to attain the target grain size prior to the forming trials. Owing to this processing design in



Fig. 10 Flow chart of processing design to perform high-strain-rate superplastic forming (HSR-SPF) of magnesium alloys with three-dimensionally shaped complicated parts. 
accordance with the flow chart shown in Fig. 10, the forming trials could be performed without repetitive trials during material preparation and forming.

The fine-grained magnesium alloy that permits highstrain-rate superplastic forming at a low temperature, i.e., below $523 \mathrm{~K}$, was prepared only by hot extrusion. Highstrain-rate superplastic forming of a boss with a height greater than $5 \mathrm{~mm}$ was successfully performed within $10 \mathrm{~s}$. The high-strain-rate superplastic forming of magnesium alloys, which were developed in the present study, has an advantage over the conventional plastic forming process with regard to low temperature at which it can be performed.

\section{Acknowledgments}

The authors (T.M. and K.H.) gratefully acknowledge the financial support of "the Priority Group of Platform Science and Technology for Advanced Magnesium Alloys, Ministry of Culture, Science and Education" (11225209). Also, this work was supported in part by the Light Metal Education Foundation Inc.

\section{REFERENCES}

1) Y. Kojima, T. Aizawa, S. Kamado and K. Higashi: Mater. Sci. Forum 419-422 (2003) 3-20.

2) T. Ito: Magnesium Manual, (Japan Magnesium Ass., Tokyo, 1999) pp. 133-134.

3) I. J. Polmear: Mater. Sci. Tech. 10 (1994) 1-16.

4) K. Saito: Materia Japan 38 (1999) 321-324.

5) F. Czerwinski, A. Zielinska-Lipiec, P. J. Pinet and J. Overbeeke: Acta Mater. 49 (2001) 1225-1235.

6) T. Shimizu: Alutopia 31-4 (2001) 41-44

7) S. Hama and F. Watanabe: J. Japan Inst. Light Metals 51 (2001) 514 515.

8) M. K. Khraisheh, H. M. Zbib, C. H. Hamilton and A. E. Bayoumi: Int. J. Plasticity 13 (1997) 143-164.

9) F. P. E. Dunne: Int. J. Plasticity 14 (1998) 413-433.

10) M. A. Khaleel, H. M. Zbib and E. A. Nyberg: Int. J. Plasticity 17 (2001) 277-296.

11) M. Lagos and H. Duque: Int. J. Plasticity 17 (2001) 369-386.

12) M. Mabuchi and K. Higashi: Int. J. Plasticity 17 (2001) 399-407.

13) H. Watanabe, T. Mukai, K. Ishikawa, M. Mabuchi and K. Higashi: Mater. Sci. Eng. A 307 (2001) 119-128.

14) H. Watanabe, T. Mukai, M. Mabuchi and K. Higashi: Acta Mater. 49 (2001) 2027-2037.

15) Glossary of terms used in metallic superplastic materials, Japanese Industrial Standard, JIS H 7007, (1995).

16) T. Mukai, H. Watanabe and K. Higashi: Mater. Sci. Tech. 16 (2000) 1314-1319.

17) D. Lee: Acta Metall. 17 (1969) 1057-1069.

18) R. Z. Valiev and O. A. Kaibyshev: Phys. Status Solidi (a) 44 (1977) 65 76.

19) M. Otsuka and M. Yuki: The research reports of Shibaura Institute of Technology. Natural sciences and engineering 41 (1997) 29-43.

20) T. Mohri, M. Mabuchi, N. Saito and M. Nakamura: Mater. Sci. Eng. A 257 (1998) 287-294.

21) H. Watanabe, T. Mukai and K. Higashi: Scr. Mater. 40 (1999) 477-484

22) H. Watanabe, H. Hosokawa, T. Mukai and T. Aizawa: Materia Japan 39 (2000) 347-354.
23) W. A. Wong and J. J. Jonas: Trans. Metall. Soc. AIME 242 (1968) 2271-2280.

24) H. Watanabe, T. Mukai, M. Kohzu, S. Tanabe and K. Higashi: Acta Mater. 47 (1999) 3753-3758.

25) R. S. Mishra, T. R. Bieler and A. K. Mukherjee: Acta Mater. 45 (1997) 561-568.

26) H. Watanabe, T. Mukai, K. Ishikawa and K. Higashi: Mater. Trans. 43 (2002) 78-80.

27) O. D. Sherby and J. Wadsworth: Prog. Mater. Sci. 33 (1989) 169-221.

28) H. Watanabe, H. Tsutsui, T. Mukai, M. Kohzu, S. Tanabe and K. Higashi: Int. J. Plasticity 17 (2001) 387-397.

29) H. J. Frost and M. F. Ashby: Deformation-mechanism Maps, (Pergamon Press, Oxford, 1982) pp. 44-45.

30) H. Watanabe, T. Mukai and K. Higashi: J. Japan Inst. Light Metals 51 (2001) 503-508.

31) D. H. Sastry, Y. V. R. K. Prasad and K. I. Vasu: Scr. Metall. 3 (1969) 927-930.

32) O. Sivakesavam, I. S. Rao and Y. V. R. K. Prasad: Mater. Sci. Tech. 9 (1993) 805-810.

33 ) R. O. Kaibyshev and O. Sitdikov: Proc. of ReX '96, (ReX '96 Int. Advisory Board and Org. Committee, 1997), pp. 203-209.

34) S. E. Ion, F. J. Humphreys and S. H. White: Acta Metall. 30 (1982) 1909-1919.

35) H. Takuda, S. Kikuchi and N. Hatta: J. Mater. Sci. 27 (1992) 937-940.

36) A. Mwembela, E. B. Konopleva and H. J. McQueen: Scr. Mater. 37 (1997) 1789-1795.

37) T. Mohri, M. Mabuchi, M. Nakamura, T. Asahina, H. Iwasaki, T. Aizawa and K. Higashi: Mater. Sci. Eng. A 290 (2000) 139-144.

38) Y. Chino, M. Mabuchi, K. Shimojima, Y. Yamada, C. Wen, K. Miwa, M. Nakamura, T. Asahina, K. Higashi and T. Aizawa: Mater. Trans. 42 (2001) 414-417.

39) R. O. Kaibyshev, A. M. Galiev and B. K. Sokolov: Phys. Met. Metall 78 (1994) 209-217.

40) N. G. Zaripov, A. R. Vagapov and R. O. Kaibyshev: Phys. Met. Metall. 63 (1987) 139-146.

41) R. O. Kaibyshev and N. G. Zaripov: Phys. Met. Metall. 66 (1988) 133137.

42) R. O. Kaibyshev and A. M. Galiev: Proc. of $\operatorname{ReX}$ '96, (ReX '96 Int. Advisory Board and Org. Committee, 1997), pp. 239-246.

$43)$ R. O. Kaibyshev and O. Sitdikov: Proc. of ReX '96, (ReX '96 Int. Advisory Board and Org. Committee, 1997), pp. 287-294.

44) R. O. Kaibyshev, B. K. Sokolov and A. M. Galiev: Textures and Microstructures 32 (1999) 47-63.

45) T. Mohri, T. Nishiwaki, T. Kinoshita, H. Iwasaki, M. Mabuchi, M. Nakamura, T. Asahina, T. Aizawa and K. Higashi: Mater. Trans. JIM 41 (2000) 1154-1156.

46) C. Zener and J. H. Hollomon: J. Appl. Phys. 15 (1944) 22-32.

47) M. Mabuchi, K. Kubota and K. Higashi: Mater. Trans., JIM 36 (1995) 1249-1254.

48) J. K. Solberg, J. Torklep, O. Bauger and H. Gjestland: Mater. Sci. Eng. A 134 (1991) 1201-1203.

49) H. Iwasaki, K. Yanase, T. Mori, M. Mabuchi and K. Higashi: J. Japan Soc. Powder and Powder Metall. 43 (1996) 1350-1353.

50) T. Sato, J. Kaneko and M. Sugamata: J. Japan Inst. Light Metals 42 (1992) 345-351.

51) M. Mabuchi, Y. Chino, H. Iwasaki, T. Aizawa and K. Higashi: Mater. Trans. 42 (2001) 1182-1189.

52) G. Nussbaum, P. Sainfort, G. Regazzoni and H. Gjestland, Scr. Metall. 23 (1989) 1079-1084.

53) O. D. Sherby and C. M. Young: Rate processes in plastic deformation of materials, Ed. by J. C. M. Li and A. K. Mukherjee, Metals Park, Ohio: American Society for Metals, 1975, pp. 497-541.

54) H. J. Frost and M. F. Ashby: Deformation-mechanism Maps, (Pergamon Press, Oxford, 1982) p. 153. 